\title{
Antifungal activity of selected plant extracts against Curvularia sp. infecting local purple sweet potato (Ipomoea batatas)
}

\author{
Mohd Nazri Baharon ${ }^{1 *}$, Nur Saliha Abdullah @ Zulkifli', Nur Adliza Baharom² and Sauli Mat Yunus ${ }^{3}$ \\ ${ }^{1}$ Pest and Disease Program, Industrial Crops Research Centre, MARDI Bachok,16310 Bachok, Kelantan, Malaysia. \\ ${ }^{2}$ Vegetable Program, Horticultural Research Center, MARDI Headquarters, 43400 Serdang, Selangor, Malaysia. \\ ${ }^{3}$ Breeding Program, Industrial Crops Research Center, MARDI Bachok, 16310 Bachok, Kelantan, Malaysia. \\ Email: mnazri@mardi.gov.my
}

\begin{abstract}
Aims: The present study was designed to evaluate in vitro antifungal activity of plant extracts against Curvularia sp., a causative agent of leaf blotch in local purple sweet potato crops.

Methodology and results: The plants were selected on the basis of commonly used traditional remedies. Various dilutions, 1/2,1/4,1/6,1/8 and 1/10 of black pepper, garden croton, garlic, tobacco and turmeric extracts were used for screening. The lesion characteristics on purple sweet potato leaves were collected from plots in MARDI Bachok. The "poisoning agar technique method" was used to get the antifungal activity. The results of antifungal activities were reported in terms of inhibition of mycelial growth of the test fungus. Out of five types of plant extracts used, only garlic and tobacco showed significantly high antifungal activity against the test pathogen based on poisoned food technique. Garlic extract showed complete inhibition (100\%) at $1 / 2$ dilution and more than $94 \%$ growth inhibition at concentrations as low as 1/10 dilution after seven days of incubation. However, black pepper and turmeric extracts showed moderate inhibition (20-70\%) whereas, no inhibition was recorded in 1/8 and 1/10 dilution of garden croton extract.

Conclusion, significance and impact of study: Our findings suggested that garlic extract is the most potential antifungal agent against Curvularia sp. and can be used as bio-fungicide thus would reduce the dependency on synthetic fungicides by farmers.
\end{abstract}

Keywords: Antifungal, purple sweet potato, Curvularia sp., plant extract

\section{INTRODUCTION}

Purple sweet potato is one of the major tuber crops grown on bris sandy soil (BRIS) and is cultivated mostly in rural areas for local food products. Fungal pathogens cause a moderate threat to purple sweet potato leaves that sometimes require the use of chemicals fungicide. The chemical can be harmful or toxic to human. Curvularia sp., which is common in soil, is one of the facultative pathogens of purple sweet potato leaf disease. Most Curvularia sp. is found in tropical regions, though a few are found in temperate.

There is a large demand for new and safer fungicide to be used in food production and agriculture. Recently, there has been a growing trend to evaluate the antifungal activity of the plant extracts, due to reduced resistance of pathogens, negative effect of chemical fungicide, safety concern and cost of food product. Black pepper (Piper nigrum), garden croton (Codiaeum variegatum), garlic (Allium sativum), tobacco (Nicotiana tabacum) and turmeric (Curcuma longa) were used in the experiment where the selection was based on previous report on preservative actions towards pathogen of these local ornamental plants. Turmeric has an active ingredient called "curcumin" reported to have antimicrobial effects on fungi, bacteria and protozoa (Mioranza et al., 2017). "Piperine" is an active ingredient contained in black pepper and can act as an antimicrobial in fungi (Mioranza et al., 2017). It was also reported that the garden croton (C. variegatum Linn.) able to control Alternaria alternate and Fusarium oxysporum. The garden croton is an example of the most common plant in the experiment that has not been fully explored. Naidu (1988) carried out the studies about thirty years ago on antifungal effect of aqueous crude extract of young and mature leaves of garden croton for their antifungal effect on $A$. alternate and $F$. oxysporum and reported that young leaves are being more active against $A$. alternata whereas old leaves more active against $F$. oxysporum.

Garlic exhibited the strongest antibacterial activity against bacterial wilt of tomato in vitro and in vivo followed by Datura sp. and then Nerium sp. (Lopes and Boiteuk, 1994; Abo-Elyousr and Asran, 2009). The antimicrobial effects of tobacco leaves using ethanol and water showed 
Malays. J. Microbiol. Vol 15(4) Special Issue 2019, pp. 342-345 DOI: http://dx.doi.org/10.21161/mjm.1915411

that the extract can inhibit the growth of Staphylococcus aureus and Escherichia coli (Okorondu et al., 2015).

Therefore, the present study was an attempt to evaluate the antifungal activity of five local ornamental plant extract viz. black pepper dried seed or referred as peppercorns, garden croton leaves, garlic bulb, tobacco leaves and turmeric rhizome against Curvularia leaf blotch pathogen of sweet potato.

\section{MATERIALS AND METHODS}

\section{Collection and isolation of Curvularia sp. isolates}

Purple sweet potato leaves with lesions characteristic of blotch were collected from plots in MARDI Bachok, Kelantan (Figure 1). These lesions are same as per literature review described by Lopes and Boiteuk (1994). To obtain isolates, a small piece of dried tissue $(5 \times 5$ $\mathrm{mm}$ ) was excised from the lesion and cultured on water agar (WA). After incubation overnight at $25^{\circ} \mathrm{C}$, grown mycelium were transferred aseptically to potato dextrose agar (PDA) and incubated at $25^{\circ} \mathrm{C}$ in the dark for two weeks. From the taxonomic classification, the cultures were observed in the laboratory to determine the pathogen as a Curvularia sp. All characteristic that observed were similar with Curvularia sp. described by Lopes and Boiteuk (1994).

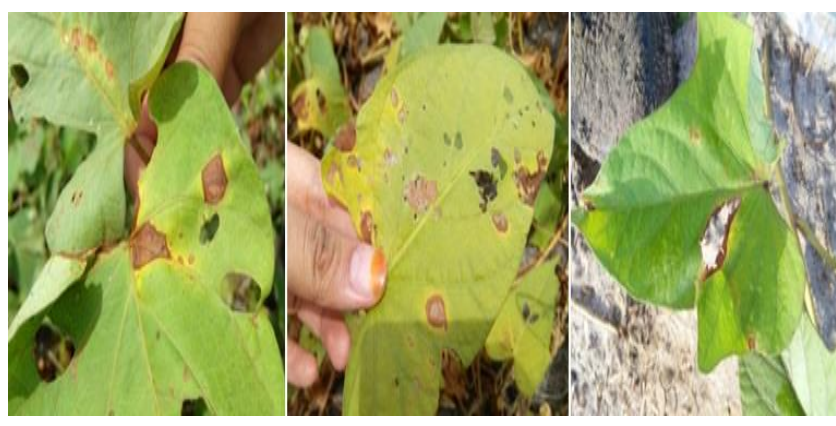

Figure 1: Symptoms of Curvularia leaf blotch on purple sweet potato.

\section{Antifungal activity}

The percentage of mycelial growth inhibition was determined using agar "poisoning agar technique method" (Rahman et al., 2009) with modification. Three-week-old culture of Curvularia sp. was plugged out using cork borer and put onto five different types of "poisoning agar" containing plant extract of black pepper, garden croton, garlic, tobacco and turmeric. Plates were prepared by adding plant extract to the PDA based on the ratio of $1 / 2$, $1 / 4,1 / 6,1 / 8$ and 1/10. A $10 \mathrm{~mm}$ mycelia plug of Curvularia $\mathrm{sp}$. was cultivated at the centre of the plate, and incubated at $25{ }^{\circ} \mathrm{C}$. The negative control plate was prepared in the same way using the sterile distilled water instead of the test solution extract. Fungal growth inhibition was done by measuring the largest diameter of the colony after several days, until the negative control plates were completely full. Three replicate plates were used per/treatment. Control, non-extract-amended PDA plates were included as reference of fungal colony growth.

The effective concentration of diluted plant extract that inhibited $50 \%$ and more of the fungal colony growth was estimated by using following formula (Vincent, 1947):

$$
\mathrm{I}=\frac{\mathrm{C}-\mathrm{T}}{\mathrm{C}} \times 100
$$

Where,

I = percent inhibition

$\mathrm{C}=$ colony diameter in control

$\mathrm{T}=$ colony diameter in treatment

The data was recorded in triplicates and conclusion was drawn on the basis of analysis of means.

\section{RESULTS AND DISCUSSION}

The results of five different dilutions of five selected plant extracts are given in Table 1 and graphical representation of antifungal activity of Curvularia sp. of purple sweet potato is shown in Figure 2. Among the different plants whose extracts were found to be effective, garlic bulbs showed maximum potential. Garlic bulbs completely inhibited the growth of Curvularia sp. at a concentration of two-fold dilution (100\%) and recorded to inhibit more than $94 \%$ even at ten-fold dilution.

Garlic or A. sativum is well-known to control diseases especially against human pathogens (Samuel et. al., 2000) and also against plant pathogens (Sindhan et. al., 1999). The growth of Curvularia sp. was inhibited with black pepper and tobacco extracts where the growth percentages were $52-70 \%$ and $74-88 \%$ respectively. The minimum inhibitory concentration (MIC) study showed that all dilutions of three plants extract namely, garlic, black pepper and tobacco inhibited more than $50 \%$ while the remaining two inhibited less than $50 \%$ except for two- and four-fold dilution of turmeric extract. No inhibition was recorded at eight-fold and ten-fold dilution of garden croton.

High inhibitory effect of black pepper also was found in a report by Shiva Rani et al. (2013) which indicates that the growth of $F$. oxysporum and $A$. alternate were only 17 and $19 \mathrm{~mm}$ colony of diameter, respectively. The in vitro application of tobacco extract showed complete inhibition of growth at $60 \%$ concentration and more than $50 \%$ inhibition even at 20\% concentration against Aspergillus viridae and Penicillium digitatum (Suleiman, 2011) which is similar to the result of this experiment. The result of turmeric inhibition is in agreement with findings reported in research by Jayaprakasha et al. (2001) where rhizome extract of turmeric showed toxicity towards Aspergillus flavus and Trichoderma viride only at higher concentrations. But the inhibitory effect of turmeric extract was contrast to the findings by Saha et al. (2005) where turmeric aqueous extracts was found to be very effective 
against Curvularia eragrostidis with a record of $98.2 \%$ of inhibition. Different chemical compounds particularly in different species of plant and also the method of extraction can be responsible for the differences in antifungal activity.
It is evident from this work that garlic followed by tobacco and black pepper extract is efficient to control the sweet potato from Curvularia sp. leaf blotch infestation. The plant extracts have high potential to be developed as bio-control agents for sweet potato disease caused by Curvularia sp.

Table 1: Effect of poisoning agar on the growth of Curvularia sp. frequently found on purple sweet potato leaves blotch (data shown are percentage value of growth inhibition on PDA).

\begin{tabular}{|c|c|c|c|}
\hline & & Fungi sp./Dilution & Curvularia sp. \\
\hline & & $1 / 2$ & 54 \\
\hline & & $1 / 4$ & 52 \\
\hline & Black pepper & $1 / 6$ & 65 \\
\hline & & $1 / 8$ & 70 \\
\hline & & $1 / 10$ & 67 \\
\hline & & $1 / 2$ & 27 \\
\hline & & $1 / 4$ & 6 \\
\hline & Garden croton & $1 / 6$ & 6 \\
\hline & & $1 / 8$ & - \\
\hline & & $1 / 10$ & - \\
\hline & & $1 / 2$ & 100 \\
\hline & & $1 / 4$ & 99 \\
\hline \multirow[t]{13}{*}{ Plant extract } & Garlic & $1 / 6$ & 99 \\
\hline & & $1 / 8$ & 96 \\
\hline & & $1 / 10$ & 94 \\
\hline & & $1 / 2$ & 88 \\
\hline & & $1 / 4$ & 84 \\
\hline & Tobacco & $1 / 6$ & 83 \\
\hline & & $1 / 8$ & 79 \\
\hline & & $1 / 10$ & 74 \\
\hline & & $1 / 2$ & 70 \\
\hline & & $1 / 4$ & 56 \\
\hline & Tumeric & $1 / 6$ & 37 \\
\hline & & $1 / 8$ & 34 \\
\hline & & $1 / 10$ & 28 \\
\hline
\end{tabular}

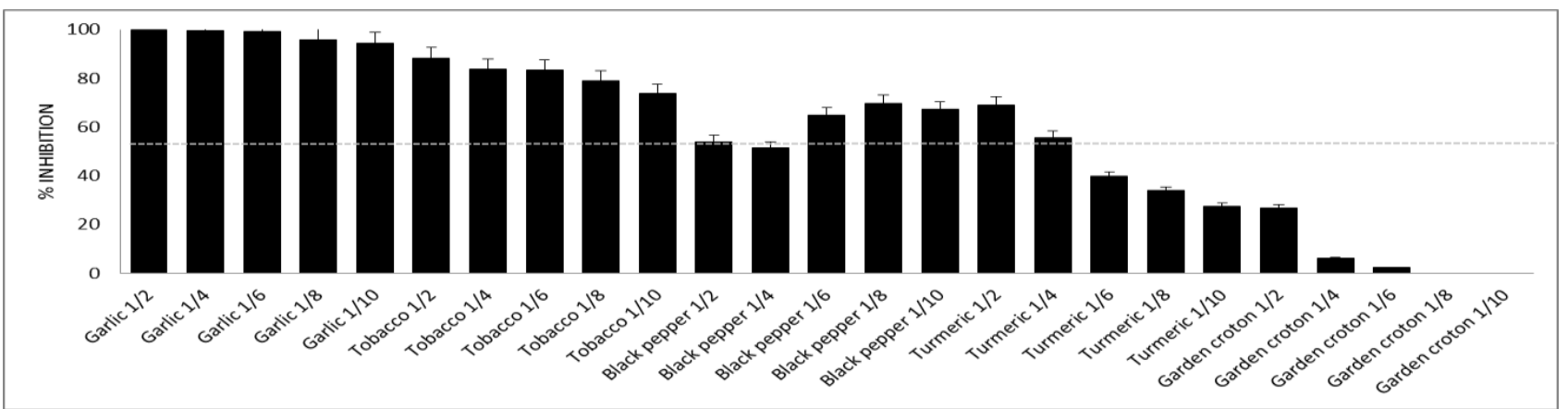

Figure 2: Antifungal activity comparison of several dilution of plant extract against Curvularia sp. by the poisoning agar assay. Data given are mean of triplicate. 
Malays. J. Microbiol. Vol 15(4) Special Issue 2019, pp. 342-345 DOI: http://dx.doi.org/10.21161/mjm.1915411

\section{CONCLUSION}

The antifungal potential of garlic, tobacco, black pepper, turmeric, and garden croton offers a broader fungicidal spectrum against tested fungi. The study indicated that garlic has strong antifungal activity followed by tobacco. Further research on purification and formulation may be needed to confirm the true value of antifungal activity of the extracts comparable to standard antifungal.

\section{ACKNOWLEDGEMENTS}

This research was supported by the funds of the sweet potato product development project $\mathrm{P}-\mathrm{RH} 403$. We would like to thank our laboratory staffs for being very helpful to run this research.

\section{REFERENCES}

Abo-Elyousr, K. A. M. and Asran, M. R. (2009) Antibacterial activity of certain plant extracts against bacterial wilt of tomato. Archives of Phytopathology and Plant Protection 42(6), 573-578.

Jayaprakasha, G. K., Negi P. S, Anandharamakrishnan, C. and Sakariah, K. K. (2001). Chemicals constituent of turmeric oil - A byproduct from turmeric oleoresin industry and its inhibitory activity against different fungi. Zeitschrift für Naturforschung C 56, 40-44.

Lopes, C. A. and Boiteuk, L. S. (1994). Leaf spot and stem blight of sweetpotato caused by Alternaria bataticola: A new record to South America. Plant disease 78(11),1107-1109.

Mioranza, T. M., Stangarlin, J. R., Kuhn, O. J., Portz, R. L., Balbi-Peña, M. S., Schwan-Estrada, K. R. F., Assi, L., Formentini, H. M., Viecelli, C. A., Dal' Maso, E. G. and Meinerz, C. C. (2017). Biological properties of turmeric. Scientia Agraria Paranaensis 16(1), 1-12.

Naidu, G. P. (1988). Antifungal activity in Codiaeum variegatum leaf extract. Current Science 57(9), 502504.

Okorondu, S. I, Okorondu, M. M. O. and Oranusi, S. C. (2015). Antimicrobial effect of Nicotiana tabacum (tobacco) leaf extract on Staphylococcus aureus and Escherichia coli. Nigerian Journal of Microbiology 29, 3049-3061.

Rahman, M. A., Begum, M. F. and Alam, M. F. (2009). Screening of trichoderma isolates as a biological control agent against ceratocystis paradoxa causing pineapple disease of sugarcane. Mycobiology 37(4), 277-285.

Saha, D., Dasgupta, S. and Saha, A. (2005). Antifungal activity of some plant extracts against fungal pathogens of tea (Camellia sinensis). Pharmaceutical Biology 43, 87-91.

Samuel, J. K., Andrews, B. and Jebashree, H. S. (2000). In vitro evaluation of the antifungal activity of Allium sativum bulb extract against Trichophyton rubrum, a human skin pathogen. World Journal of Microbiology and Biotechnology 16, 617-620.

Shiva Rani, S. K., Saxena, N. and Udaysree. (2013). Antimicrobial activity of black pepper (Piper nigrum L.). Global Journal of Pharmacology 7, 87-90.

Sindhan, G. S., Hooda, I. and Parashar, R. D. (1999). Effect of some plant extract on the vegetative growth of root rot causing fungi. Journal of Mycology and Plant Pathology 29, 110-111.

Suleiman, M. N. 2011. Antifungal properties of leaf extract of neem and tobacco on three fungal pathogens of tomato (Lycopersion exculetum Mill.). Advanced in Applied Science Research 2(4), 217-220.

Vincent, J. M. (1947). Distortion of fungal hyphae in presence of certain inhibitors. Nature 1947 159, 239241. 